\title{
Poisoning by organophosphorus insecticides and sensory neuropathy
}

\author{
Angelo Moretto, Marcello Lotti
}

\begin{abstract}
Objectives-Poisoning by organophosphate insecticides causes cholinergic toxicity. Organophosphate induced delayed polyneuropathy (OPIDP) is a sensorymotor distal axonopathy which usually occurs after ingestion of large doses of certain organophosphate insecticides and has so far only been reported in patients with preceding cholinergic toxicity. Surprisingly, it was recently reported by other authors that an exclusively sensory neuropathy developed in eight patients after repeated unquantified exposures to chlorpyrifos, which did not cause clear-cut cholinergic toxicity. The objective was to assess whether an exclusively sensory neuropathy develops in patients severely poisoned by various OPs.

Methods-Toxicological studies and electrophysiological measurements were performed in peripheral motor and sensory nerves in 11 patients after acute organophosphate poisoning among which two subjects were poisoned with chlorpyrifos. Results-Three patients developed OPIDP, including one poisoned by chlorpyrifos. Exclusively sensory neuropathy was never seen after either single or repeated acute organophosphate poisoning. A mild sensory component was associated with a severe motor component in two of the three cases of OPIDP, the other was an exclusively motor polyneuropathy.

Conclusion-A sensory-motor polyneuropathy caused by organophosphate insecticides might occur after a severe poisoning and the sensory component, if present, is milder than the motor one. Bearing in mind the toxicological characteristics of these organophosphate insecticides, other causes should be sought for sensory peripheral neuropathies in patients who did not display severe cholinergic toxicity a few weeks before the onset of symptoms and signs.

(F Neurol Neurosurg Psychiatry 1998;64:463-468)
\end{abstract}

Keywords: organophosphorus insecticide poisoning; sensory neuropathy; delayed polyneuropathy

Several organophosphorus esters are used as insecticides because they inhibit the acetylcholinesterase (AChE) of insects. ${ }^{1}$ The same mechanism accounts for acute toxicity in humans and is is characterised by signs of cholinergic overstimulation. ${ }^{2}$ In addition, certain organophosphates may cause a distal, sensory-motor, central-peripheral axonopathy known as organophosphate induced delayed polyneuropathy (OPIDP). ${ }^{34}$

The toxicological characteristics of organophosphates currently in use as insecticides have been assessed in animals. ${ }^{5}$ These organophosphates are more potent inhibitors of AChE than of neuropathy target esterase (NTE), which is thought to be the target for OPIDP. ${ }^{4} 7$ Consequently, OPIDP was found both in hens (the animal of choice for OPIDP studies) and humans only at doses exceeding those which cause cholinergic toxicity. ${ }^{3689}$

However, it has been reported that the development of an exclusively sensory neuropathy was associated in eight patients with repeated low level exposures to the organophosphate insecticide chlorpyrifos (O,O-diethyl O-3,5,6trichloro-2-pyridylphosphorothioate). ${ }^{10} \mathrm{No}$ or mild symptoms or signs compatible with cholinergic overstimulation were reported in these patients. Possible explanations for this unexpected finding might be that sensory neuropathies in humans exposed to organophosphate insecticides have been overlooked, that animal testing is not predictive, or that chlorpyrifos itself represents an exception. Therefore, we evaluated peripheral nerve sensory function in 11 patients after acute poisoning by various organophosphates, including two patients poisoned by chlorpyrifos. Three patients developed OPIDP and in two of them a sensory component was found.

\section{Methods}

Patients underwent extensive neurological examination on several occasions. The examination of the peripheral nervous system included assessment of gait, deep tendon reflexes, muscle strength, and vibration, pin, light touch, and thermal sensitivities. Plasma butyryl cholinesterase (BuChE) was measured with commercial kits. Red blood cell, AChE, and lymphocytic neuropathy target esterase (LNTE) were determined according to Ellman et $a l^{11}$ and to Bertoncin et $a l,{ }^{12}$ respectively. Blood concentrations of organophosphates were measured by gas chromatography-mass spectroscopy. Electrophysiological studies were performed at controlled temperature as described by Kimura, ${ }^{13}$ two to six weeks after poisoning on one or more occasions. To assess conduction velocities, surface electrodes were used to stimulate the nerves whereas bipolar concentric needle and surface electrodes were used to record muscle and sensory potentials respectively. The following nerves were assessed: ulnar (stimulation below the elbow and at the wrist, recording at the abductor digiti in revised form 13 August 1997

Accepted 9 September 1997 
Table 1 Toxological data from patients poisoned with organophosphates

\begin{tabular}{|c|c|c|c|c|c|}
\hline Case No (compound) & $\begin{array}{l}\text { Time after } \\
\text { poisoning }\end{array}$ & $\begin{array}{l}\text { Red blood cell AChE } \\
\text { (mU/l) (normal } \\
4.9-11.7)\end{array}$ & $\begin{array}{l}\text { Plasma BuChE } \\
(\mathrm{mU} / \mathrm{l}) \text { (normal } \\
2.4-8.3)\end{array}$ & $\begin{array}{l}\text { Lymphocyte-NTE } \\
\text { (mU/g protein) (normal } \\
6.5-16.5 \text { ) }\end{array}$ & $\begin{array}{l}\text { Blood } \\
\text { concentration } \\
\text { ( } \text { momolll) }\end{array}$ \\
\hline 1 (Methidathion) & $\begin{array}{l}12 \mathrm{~h} \\
3 \text { days }\end{array}$ & $<0.5$ & $<0.5$ & $10.7 \dagger$ & $5.6^{\star}$ \\
\hline 2 (Azinphos-methyl) & $\begin{array}{l}12 \mathrm{~h} \\
2 \text { days }\end{array}$ & 0 & 0 & $8.2 \dagger$ & ND \\
\hline 3 (Coumaphos) & $10 \mathrm{~h}$ & 0 & 0 & $8.6 \dagger$ & ND \\
\hline $\begin{array}{l}4 \text { (Coumaphos) } \\
5 \text { (Coumaphos) }\end{array}$ & $\begin{array}{l}3 \mathrm{~h} \ddagger \\
2 \mathrm{~h}\end{array}$ & $<0.5$ & 0 & ND & $\begin{array}{l}0.06 \\
0.08\end{array}$ \\
\hline & $20 \mathrm{~h}$ & 2.0 & $<0.5$ & 12.5 & \\
\hline 6 (Chlorpyrifos) & $\begin{array}{l}15 \mathrm{~h} \\
40 \text { days }\end{array}$ & 5.9 & $\begin{array}{r}<0.5 \\
1.6\end{array}$ & 9.5 & ND \\
\hline 7 (Isofenphos) & $10 \mathrm{~h}$ & 0 & 0 & $5.9 \rrbracket$ & ND \\
\hline 8 (Trichlorfon) & $\begin{array}{r}4 \mathrm{~h} \\
24 \mathrm{~h}\end{array}$ & ND & 0 & $9.2 \dagger$ & ND \\
\hline 9 (Chlorpyrifos) & $\begin{array}{l}3 \text { days } \\
30 \text { days }\end{array}$ & 3.6 & $\begin{array}{l}<0.5 \\
<0.5\end{array}$ & $5.9^{\star \star}$ & 0.79 \\
\hline 10 (Methamidophos) & $\begin{array}{l}8 \mathrm{~h} \\
21 \mathrm{~h}\end{array}$ & $<0.5$ & $<0.5$ & $1.0+t$ & $27.0^{\star}$ \\
\hline $\begin{array}{l}11 \text { (Isofenphos + } \\
\text { phoxim) }\end{array}$ & $3 \mathrm{~h}$ & $<0.5$ & $<0.5$ & ND & $\begin{array}{c}10.1 \neq+ \\
0.3 \$ \S\end{array}$ \\
\hline
\end{tabular}

* Half life of about 10 hours. $\dagger$ Within normal range also at later measurements. $\ddagger$ Refers to the last episode. $\$ Within normal values on day $3(10.0 \mathrm{mU} / \mathrm{g}$ protein). T Half life of about 2 days, but the chemical was detected up to 10 days after poisoning.

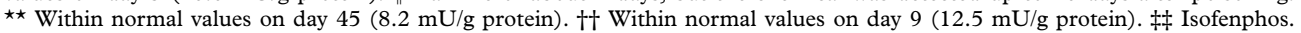
If Phoxim. $\mathrm{ND}=$ not done. $\mathrm{AChE}=$ acetyl cholinesterase; $\mathrm{BuChE}=$ butyryl cholinesterase; NTE $=$ neuropathy target esterase.

minimi muscle), median (stimulation at the wrist and at the elbow, recording at the abductor pollicis brevis muscle; sensory: stimulation at the third finger, recording at the wrist), common peroneal (stimulation below the head of the fibula and at the ankle, recording at the extensor digitorum brevis muscle), sural (antidromic stimulation $14 \mathrm{~cm}$ proximally to the recording site below the lateral malleolus). Standard concentric needles were used for the EMG examination. The abductor pollicis brevis and the extensor digitorum brevis muscles were assessed; when data were abnormal, more proximal muscles were studied.

\section{Case presentation}

Table 1 shows the enzyme inhibition and organophosphate concentrations in blood of poisoned patients. Table 2 shows a summary of the electrophysiological studies in patients with OPIDP.

GROUP 1: POISONING BY ORGANOPHOSPHATES NOT KNOWN TO CAUSE OPIDP WHICH DID NOT RESULT IN CLINICAL OR ELECTROPHYSIOLOGICAL SIGNS OF NEUROPATHY

Case 1

A 50 year old man attempted suicide by ingesting a commercial formulation of methidathion (S-2,3-dihydro-5-methoxy-2-oxo-1,3,4thiadiazol-3-ylmethyl O,O-dimethyl phosphorodithioate). The estimated dose was $6 \mathrm{~g}$. $\mathrm{He}$ was comatose for four days and was treated with pralidoxime (up to $1 \mathrm{~g}$ /day intravenously for nine days), atropine (up to $12 \mathrm{mg} /$ day intravenously for 15 days), and artificial ventilation (for 15 days). This case has been partly described previously. ${ }^{14}$

Case 2

An 82 year old man attempted suicide by ingesting an unknown amount of a commercial formulation of azinphos-methyl (S-3,4dihydro-4-oxo-1,2,3-benzotriazin-3-ylmethyl $\mathrm{O}, \mathrm{O}-$ dimethyl phosphorodithioate). He was comatose for five days and was treated with pralidoxime (400 mg intravenously at admission), atropine (up to $30 \mathrm{mg} /$ day intravenously for 15 days), and artificial ventilation (for nine days).

GROUP 2: POISONING BY ORGANOPHOSPHATES KNOWN TO CAUSE OPIDP WHICH DID NOT RESULT IN CLINICAL OR ELECTROPHYSIOLOGICAL SIGNS OF NEUROPATHY

Case 3

A 39 year old woman attempted suicide by ingesting a commercial formulation of coumaphos (O-3-chloro-4-methyl-2-oxo-2H-chromen-7-yl O,O-diethyl phosphothioate). The estimated dose was $4 \mathrm{~g}$. She was comatose for two days and was treated with pralidoxime (up to $2.5 \mathrm{~g}$ /day intravenously for seven days), atropine (up to $22 \mathrm{mg}$ /day intravenously, for eight days), and artificial ventilation (for nine days).

Case 4

A 32 year old man was repeatedly administered unknown amounts of organophosphate (s) over a five month period for homicidal purposes, presumably always coumaphos because this chemical was found in his meals (and in his blood) at the time of the last episode. The first poisoning was mild and short lasting (few hours). A second, more severe episode occurred some days later. He was comatose for two days and was treated with pralidoxime (up to $2 \mathrm{~g}$ /day intravenously for 12 days), atropine (up to $10 \mathrm{mg} /$ day intravenously for 12 days), and artificial ventilation (for four days). He was discharged on day 26 from the first episode. During the next four months he had eight more episodes of mild or moderate toxicity and was treated with pralidoxime (up to $1.2 \mathrm{~g}$ /day intravenously for up to three days) and atropine (up to $2 \mathrm{mg} /$ day intravenously for up to four days). Eventually, coumaphos was detected in the parmesan cheese brought to him from outside the hospital. 
Table 2 Summary of electrophysiological data in patients with OPIDP

\begin{tabular}{|c|c|c|c|c|c|c|c|c|}
\hline \multirow[b]{2}{*}{ Case No (compound) } & \multirow[b]{2}{*}{$\begin{array}{l}\text { Day after } \\
\text { poisoning }\end{array}$} & \multicolumn{3}{|l|}{ Motor ${ }^{*}$} & \multicolumn{3}{|l|}{ Sensory ${ }^{*}$} & \multirow[b]{2}{*}{ Notes } \\
\hline & & Nerve & $C V(\mathrm{~m} / \mathrm{s})$ & $\begin{array}{l}C M A P \\
(m / V)\end{array}$ & Nerve & $C V(\mathrm{~m} / \mathrm{s})$ & $\begin{array}{l}S A P \\
(\mu V)\end{array}$ & \\
\hline \multirow[t]{4}{*}{9 (Chlorpyrifos) } & \multirow[t]{2}{*}{24} & Common peroneal & 50 & 15 & & & & \multirow{6}{*}{$\ddagger$} \\
\hline & & Ulnar & $55-60$ & 20 & & & & \\
\hline & \multirow[t]{2}{*}{62} & Common peroneal & $41-44$ & $8 \dagger$ & & & & \\
\hline & & Ulnar & $48-52$ & $12 \dagger$ & Ulnar & 44 & 2 & \\
\hline \multirow[t]{5}{*}{10 (Methamidophos) } & \multirow[t]{2}{*}{10} & \multirow[t]{2}{*}{ Common peroneal } & \multirow[t]{2}{*}{47} & \multirow[t]{2}{*}{8} & Sural & 54 & 9 & \\
\hline & & & & & Ulnar & 53 & 4 & \\
\hline & \multirow[t]{3}{*}{34} & Common peroneal & 40 & 0.1 & Sural & 44 & 11 & \multirow[t]{3}{*}{$\S$} \\
\hline & & Median & 60 & 3 & & & & \\
\hline & & Ulnar & 54 & 15 & Ulnar & 55 & 6 & \\
\hline \multirow{4}{*}{$\begin{array}{l}11 \text { (Isofenphos }+ \\
\text { phoxim) }\end{array}$} & 26 & Common peroneal & 22 & 0.3 & & & & ๆ \\
\hline & \multirow{3}{*}{700} & Median & 50 & 0.3 & Median & 60 & 13 & \multirow{3}{*}{$\star \star$} \\
\hline & & Common peroneal & Not measurable & & & & & \\
\hline & & Median & 25 & 0.2 & Median & 71 & 10 & \\
\hline
\end{tabular}

* Reference values were: motor conduction velocity $(\mathrm{CV})$ : common peroneal $\geqslant 45$, ulnar $\geqslant 50$, median $\geqslant 48$; sensory conduction velocity: sural $\geqslant 48$, ulnar $\geqslant 53$, median $\geqslant 48$; compound motor action potential (CMAP): common peroneal $\geqslant 5$, ulnar $\geqslant 6$, median $\geqslant 7$; sensory action potentials $(\mathrm{SAP})$ : sural $\geqslant 6$, ulnar $\geqslant 4$, median $\geqslant 7$.

† An increased frequency of polyphasic potentials was found. $\ddagger$ Fibrillation potentials were present in distal leg muscles, but not in arm muscles. $\$$ Fibrillation potentials were present in both leg and arm distal muscles. $\uparrow$ In subsequent electrophysiological studies motor and sensory CVs were not measurable and severe signs of denervation (fibrillation potentials) were found in arm, and especially, leg muscles. ${ }^{\star \star}$ Signs of denervation (fibrillation potentials) were still present and much less evident in both arm (only distally) and leg muscles. Partial reinnervation took place (scarce interference pattern with high frequency potentials) in arm muscles and to a lesser extent in proximal leg muscles.

Case 5

A 23 year old woman attempted suicide by ingesting an unknown amount of a commercial formulation of coumaphos. She was comatose for 12 hours and was treated with pralidoxime ( $4 \mathrm{~g} /$ day intravenously for two days), atropine (12 $\mathrm{mg}$ /day intravenously for three days), and artificial ventilation (for four days).

Case 6

A 78 year old man attempted suicide by ingesting an unknown amount of a commercial formulation of chlorpyrifos. He was comatose for five days and was treated with pralidoxime (up to $12 \mathrm{~g} /$ day intravenously for five days) and atropine (up to $2.5 \mathrm{mg}$ /day intravenously for six days). Artificial ventilation was continued for 21 days because of pneumonia for which he was treated with antibiotics for about six weeks.

Case 7

An 80 year old man attempted suicide with self injection (subcutaneously and intramuscularly) of a commercial formulation of isofenphos (isopropyl O-(ethoxy-N-isopropylamino (phosphoryl))salicilate). The stimated dose was $1.5 \mathrm{~g}$. He was comatose for six days and was treated with pralidoxime (up to $1.6 \mathrm{~g}$ /day intravenously for 10 days), atropine (up to 12 $\mathrm{mg}$ /day intravenously for 10 days), and artificial ventilation (for 10 days). Electrophysiological studies performed on day 16 were normal. He developed severe pneumonia and died on day 32 .

Case 8

A 53 year old woman attempted suicide by ingesting a commercial formulation of trichlorfon (dimethyl 2,2,2-trichloro-1-hydroxyethylphosphonate). The estimated dose was $1.6 \mathrm{~g}$. She was treated with pralidoxime $(800 \mathrm{mg}$ intravenously on admission) and atropine (up to $2.5 \mathrm{mg}$ /day intravenously for seven days). Assisted ventilation was not necessary.
GROUP 3: POISONING BY ORGANOPHOSPHATES WHICH RESULTED IN OPIDP

Case 9

A 42 year old man attempted suicide by ingesting an unknown amount of a commercial formulation of chlorpyrifos. He was comatose for seven days and was treated with pralidoxime (up to $2.5 \mathrm{~g}$ /day intravenously for 23 days), atropine (up to $8 \mathrm{mg} /$ day intravenously for 10 days), and artificial ventilation (for 17 days). He was treated with antibiotics for about three weeks because of pneumonia. He was asymptomatic by day 24 after poisoning when neurological examination was unrevealing and electrophysiological studies of motor nerves were normal. On day 43, he began to complain of weakness and paraesthesiae of the legs. On day 62 , the patient had some gait impairment and showed loss of tendon reflexes and of vibration sense in the legs. Electrophysiological data obtained at this time were indicative of OPIDP with both sensory and motor components (table 2). After about three months the clinical and electrophysiological conditions were unchanged (data not shown). The patient was lost to follow up. This case has been partly described previously. ${ }^{15}$

\section{Case 10}

A 32 year old man attempted suicide by ingesting a commercial formulation of methamidophos (O,S-dimethyl phosphoroamidothioate). The estimated dose was $40 \mathrm{~g}$. He was comatose for four days and was treated with pralidoxime (up to $8 \mathrm{~g} /$ day intravenously for eight days), atropine (up to $12 \mathrm{mg} /$ day intravenously for eight days,) and artificial ventilation (for six days). He developed pneumonia and was treated with antibiotics for a few days. Electrophysiology of motor and sensory nerves was normal 10 days after poisoning. The patient was discharged asymptomatic two weeks after poisoning. However, on day 25 he began to complain of leg weakness. No sensory alterations were recorded at physical examination. 
Electrophysiological data were indicative of a purely motor neuropathy of the lower limbs (table 2). About two months later the clinical and electrophysiological conditions were unchanged (data not shown). The patient died a few weeks later in a car accident.

Case 11

A 26 year old man voluntarily ingested a commercial formulation of isofenphos and phoxim (diethoxyphosphinothioyloxyimino (phenyl) acetonitrile). Estimated doses were 35 and $9 \mathrm{~g}$ respectively. He was treated with atropine ( 7 $\mathrm{mg} /$ day intravenously) and pralidoxime (8 g/day intravenously). Treatment lasted five days with tapering off over the next seven days. Cholinergic signs were detectable only for about one day and artificial ventilation was not needed. The patient was discharged asymptomatic on day 17. A few days later, he complained of lower limb paraesthesia and weakness. Within four days, he developed flaccid tetraplegia. On day 26 , electrophysiological data were consistent with severe motor neuropathy (table 2 ). No sensory alterations were recorded at physical examination. Subsequently, severe motor denervation was evident in his arms and legs lasting for several months along with signs of sural and sensory median nerve damage (data not shown). After 22 months the clinical condition of his arms greatly improved. Partial recovery was also evident in the his legs although he developed spastic paraparesis. Electrophysiological studies performed at this time were indicative of some axonal regeneration of peripheral nerves.

\section{Discussion}

Neuropathy was not expected in patients of group 1, despite severe cholinergic toxicity, because neither methidathion nor azinphosmethyl cause OPIDP in hens ${ }^{16}{ }^{17}$ when tested at or above the $\mathrm{LD}_{50}$ and no cases in humans have ever been reported. Moreover L-NTE was not inhibited in these cases. High L-NTE inhibition measured soon after exposure is thought to herald the development of OPIDP. ${ }^{15} 18$

Neuropathy may have been expected in patients of group 2 because the involved organophosphates cause OPIDP in hens and cases were also reported in humans. OPIDP did not develop, likely because of insufficient doses, although the doses were high enough to cause severe cholinergic toxicity. Coumaphos causes OPIDP in hens, ${ }^{19}$ but neuropathy was not reported in humans after acute poisoning. ${ }^{20}$ Moreover, L-NTE was not inhibited in two of our three patients poisoned with coumaphos (cases 3-5). Chlorpyrifos causes OPIDP both in humans (case 9) and hens, ${ }^{21}$ but did not in case 6 . The patient poisoned with isophenfos (case 7) showed about 50\% L-NTE inhibition soon after dosing but he died on day 32 , and OPIDP might have developed after this time. Isophenfos causes OPIDP both in humans ${ }^{22} 23$ (also case 11) and in hens, ${ }^{24}$ as does trichlorfon ${ }^{25} 26$ but patient 8 had a relatively mild poisoning and her L-NTE was not inhibited.
Patients of group 3 (cases 9-11, table 2) developed OPIDP and the inhibition of L-NTE was predictive (cases 9 and 10). Other causes of neuropathy such as diabetes, alcoholism, uraemia, porphyrias, and trauma have been excluded. The sensory component of polyneuropathy in the patient poisoned by chlorpyrifos was mild both when symptoms and signs first appeared and when they fully developed. The patient poisoned with methamidophos displayed a purely motor neuropathy. When electrophysiology was performed during the silent period between poisoning and onset of polyneuropathy, the motor-sensory function was normal. In previously reported cases of OPIDP by methamidophos some sensory symptoms, but no objective signs, have been recorded. ${ }^{27}$ Methamidophos causes OPIDP in hens. ${ }^{28}$ In the patient poisoned by isofenphos and phoxim, sensory impairment was not detected at the onset of polyneuropathy and it recovered at later stages, when motor neuropathy was still evident. Phoxim does not cause OPIDP in hens ${ }^{29}$ and no cases of human poisoning have been reported.

Quantitative sensory examination was performed in some of the patients reported on by Kaplan et $a l,{ }^{10}$ although it was not apparently used as a diagnostic criterion. We did not perform a quantitative sensory examination either because there were no sensory symptoms or clinical and electrophysiological signs or because sensory symptoms were always associated with electrophysiological changes. ${ }^{30}$ Moreover, the relevance of electrophysiological alterations not associated with signs or symptoms is unclear. ${ }^{30}$ Therefore, the use of more sensitive and complex electrophysiological tests to assess sensory functions in subjects exposed but not poisoned by organophosphates, as suggested recently, ${ }^{31}$ does not seem justified in the absence of signs or symptoms.

In summary, the features of the cases reported here and in the medical literature indicate that:

(1) OPIDP caused by insecticides is preceded by severe cholinergic toxicity. ${ }^{9}$

(2) An exclusively sensory neuropathy does not occur after severe cholinergic poisoning by organophosphates.

(3) Mild sensory neuropathy is inconsistently associated with the motor component of OPIDP $^{27}{ }^{32-35}$ and is unlikely to be a more sensitive indicator of OPIDP (by comparing cases 6 and 9 ).

These findings accord with the known toxicological characteristics of chlorpyrifos but contrast with those described in patients exposed to low concentrations of chlorpyrifos. ${ }^{10}$

Toxicological studies showed that commercial organophosphate insecticides have a very low in vitro AChE $I_{50}$ : NTE $I_{50}$ ratio with both human and hen enzymes which correlates well with the corresponding in vivo ratio (acute unprotected $\mathrm{LD}_{50}$ :single neurotoxic dose) in the hen. ${ }^{6}\left(I_{50}\right.$ is the concentration of inhibitor which inhibits $50 \%$ of the enzymatic activity in given experimental conditions.) In particular, 
the active metabolite of chlorpyrifos, chlorpyrifos-oxon, has an AChE $\mathrm{I}_{50}$ :NTE $\mathrm{I}_{50}$ ratio of 0.07 with human enzymes, which correlates with the corresponding in vitro and in vivo (with chlorpyrifos) ratios in hens. ${ }^{213637}$ Therefore, given the sensitivities of target enzymes, it is unlikely that the threshold of NTE inhibition (about $70 \%$ ) can be reached in the absence of severe cholinergic toxicity (which requires $80 \%-90 \%$ AChE inhibition), after either single or repeated doses of chlorpyrifos to humans. Moreover, it was shown that hens given repeated small doses of neuropathic organophosphates (not AChE inhibitors) tolerate very high cumulative doses without signs of OPIDP when the dosing schedule is such that rate of NTE resynthesis is higher than that of NTE inhibition. ${ }^{38}$

All but one of the patients of Kaplan et $a l^{10}$ developed sensory neuropathy within four weeks from the beginning of a reported low level repeated exposure to chlorpyrifos. Most toxic neuropathies including OPIDP are somewhat delayed. Therefore, to allow time for the development of clinical signs, a critical biochemical/pathophysiological effect in the nervous system of these patients should have been reached after about two weeks of exposure. The pharmacokinetics of chlorpyrifos is long, ${ }^{213637}$ as indicated by the lengthy cholinergic symptomatology of our patients (about one and three weeks) associated with long lasting blood concentrations of chlorpyrifos and enzyme inhibition (case 9 and table 1). Therefore it might be assumed that the chemical was present in the nervous system of our patients for at least two and four weeks, respectively. This is consistent with a reported half life of urinary elimination of chlorpyrifos metabolites reported in poisoned subjects corresponding to about 80 hours. $^{39}$ We argue that our patients also had a prolonged (at least two weeks) although declining exposure to chlorpyrifos, which was similar in time to that of the patients of Kaplan et al. ${ }^{10}$ Moreover, our patients' single dose was certainly much higher than the cumulative dose of the patients of Kaplan et al. ${ }^{10}$ If sensory neuropathy was the result of continuous additive toxicity of chlorpyrifos, then a sensory neuropathy in patient 6 and a more severe sensory component of OPIDP in patient 9 should have been found. On the contrary, the first patient did not develop neuropathy and the second had a mainly motor neuropathy with a degree of sensory impairment similar to that detected in the patients of Kaplan et $a l,{ }^{10}$ who did not display motor deficits.

We conclude that polyneuropathy may follow a severe poisoning by certain organophosphate insecticides. In our patients, the sensory component of the polyneuropathy was never an isolated finding and, if present, was mild when compared with the motor deficit. Although sensory neuropathies have been consistently associated in a series of patients with low level repeated exposures to chlorpyrifos, there is little evidence for a causal relation, because the assessment of those exposures was limited and based almost exclusively on medical history. ${ }^{10}$
Bearing in mind the toxicological characteristics of organophosphate insecticides, other causes should be sought for peripheral neuropathies in patients who did not display severe cholinergic toxicity a few weeks before the onset of the neuropathy.

We thank F Davanzo, Centro Antiveleni, Milano Italy, and R Zoppellari, Ospedale S Anna, Ferrara Italy, for case referral; the Azienda Regionale Prevenzione Ambientale, Ferrara Italy, for analytical chemistry, MJ Aminoff, University of California, San Francisco USA, for his comments, and CA Drace-Valentini for help in manuscript preparation. This work has been supported help in manuscript preparation. This work has been supported by Bayer AG, Leverkusen Germany, and by DowElanco, and not necessarily of the sponsors. The financial support of CNR, Ministero Italiano dell'Universita e della Ricerca Scienti-
fica e Tecnologica, and Regione Veneto is also gratefully acknowledged.

1 Tomlin C, ed. The pesticide manual. A world compendium, 10th ed. Bath: British Crop Protection Council, 1994

2 Taylor P. Anticholinesterase agents. In: Hardman JG, Limbird LE, eds. Goodman and Gilman's the pharmacological basis of therapeutics, 9th ed. New York: McGraw Hill, 1996:161-76.

3 Lotti M, Becker CE, Aminoff MJ. Organophosphate polyneuropathy: pathogenesis and prevention. Neurology 984;34:658-62.

4 Lotti $M$. The pathogenesis of organophosphate delayed polyneuropathy. Crit Rev Toxicol 1992;21:465-87.

5 Food and Agriculture Organization of the United Nations. foint meeting on pesticides residues in food, 1961-95 reports. Rome: FAO/WHO, 1962-96.

6 Lotti M, Johnson MK. Neurotoxicity of organophosphorus pesticides: predictions can be based on in vitro studies with hen and human enzymes. Arch Toxicol 1978;41:215-21.

7 Johnson MK. Organophosphates and delayed neuropathy-is NTE alive and well? Toxicol Appl Pharmacol 1990;102:38599.

8 Johnson MK. Organophosphorous esters causing delayed neurotoxic effects: mechanism of action and structure/ activity studies. Arch Toxicol 1975;34:259-88.

9 World Health Organization. Organophosphorus insecticides: a general introduction. Geneva: World Health Organization, 1986. (Environmental Health Criteria 63.)

10 Kaplan JG, Kessler J, Rosenberg N, et al. Sensory neuropathy associated with Dursban (chlorpyrifos) exposure. Neurology 1993;43:2193-6.

1 Ellman GL, Courtney KK, Andres W Jr, et al. A new and rapid colorimetric determination of acetylcholinesterase activity. Biochem Pharmacol 1961;7:88-95.

12 Bertoncin D, Russolo A, Caroldi S, et al. Neuropathy target esterase in human lymphocytes. Arch Environ Health 1985; 40:139-44.

13 Kimura J. Nerve conduction studies and electromyography. In: Dyck PJ, Thomas PK, Griffin JW, et al, eds. Peripheral neuropathy, 3rd ed. Vol 1. Philadelphia: WB Saunders, 1993:598-644.

14 Zoppellari R, Targa L, Tonini P, et al. Acute poisoning with methidathion: a case. Hum Exp Toxicol 1990;9:415-9.

15 Lotti M, Moretto A, Zoppellari R, et al. Inhibition of lymphocytic neuropathy target esterase predicts the development of organophosphate-induced delayed polyneuropathy. Arch Toxicol 1986;59:176-9.

16 Food and Agriculture Organization of the United Nations. foint meeting on pesticides residues in food, 1991 report. Rome: FAO/WHO, 1992:3-23.

17 FAO/WHO. Foint meeting on pesticides residues in food, 1992 report. Rome: Food and Agriculture Organization of the United Nations, 1993:233-65.

18 Lotti $M$. Organophosphate-induced delayed polyneuropathy in humans: perspectives for biomonitoring. Trends Pharmacol Sci 1987:8;175-6.

19 Abou-Donia MB, Makkawy HA, Graham DG. Coumaphos: delayed neurotoxic effect following dermal administration in hens. F Toxicol Environ Health 1982;10:87-99.

20 Fang TC, Chen KW, Wu MH, et al. Coumaphos intoxications mimics food poisoning. $\mathcal{f}$ Toxicol Clin Toxicol 1995;33:699-703.

21 Capodicasa E, Scapellato ML, Moretto A, et al. Chlorpyrifos-induced delayed polyneuropathy. Arch Toxicol 1991;65:150-5

22 Catz A, Chen B, Jutrin I, et al. Late onset of isofenphos neurotoxicity. F Neurol Neurosurg Psychiatry 1988;51:1338-40.

23 Tracey JA, Gallagher H. Use of glycopyrrolate and atropine in acute organophosphorus poisoning. Hum Exp Toxicol 1990;9:99-100.

24 Wilson BW, Hooper M, Chow E, et al. Antidotes and neuropathic potential of isofenphos. Bull Environ Contam Toxicol 1984;33:386-94.

25 Vasilescu C, Alexianu M, Dan A. A delayed neuropathy after organophosphorus insecticide (Dipterex) poisoning: a clinical, electrophysiological and nerve biopsy study. $\mathcal{F} \mathrm{Neu}$ rol Neurosurg Psychiatry 1984;47:543-8.

26 Johnson MK. Delayed neurotoxicity-do trichlorphon and/or dichlorvos cause delayed neuropathy in man or in
test animals? Acta Pharmacol Toxicol 1981;49(suppl V):87test 
27 Senanayake N, Johnson MK. Acute polyneuropathy after poisoning by a new organophosphorus insecticide. $N$ Engl F Med 1982:306:155-7.

28 Lotti M, Moretto A, Bertolazzi M, et al. Organophosphate polyneuropathy and neuropathy target esterase: studies with methamidophos and its resolved optical isomers. Arch Toxicol 1995;69:330-6.

$29 \mathrm{FAO/WHO}$. Foint meeting on pesticides residues in food, 1984 report. Rome: Food and Agriculture Organization of the United Nations, 1985:697-715.

30 Dyck PJ. Quantitating severity of neuropathy. In: Dyck PJ Thomas PK, Griffin JW, et al, eds. Peripheral neuropathy, 3rd ed. Vol 1. Philadelphia: WB Saunders, 1993:686-97.

31 Jamal GA. Long term neurotoxic effects of organophosphate compounds. Adverse Drug React Toxicol Rev 1995;14: $85-99$.

32 Hierons R, Johnson MK. Clinical and toxicological investigations of a case of delayed neuropathy in man after acute
poisoning by an organophosphorus pesticide. Arch Toxicol poisoning by an

33 Wadia RS, Shinde SN, Vaidya S. Delayed neurotoxicity after an episode of poisoning with dichlorvos. Neurology (India) $1985 ; 33: 247-53$
34 Vasilescu C, Florescu A. Clinical and electrophysiological study of neuropathy after organophosphorus compounds study of neuropathy after organophosphor

35 Bidstrup PL, Bonnel JA, Beckett AG. Paralysis following poisoning by a new organic phosphorus insecticide (mipafox). BMF 1953;i:1068-72.

36 Richardson RJ, Moore TB, Kayyali US, Randall JC. Chlorpyrifos: assessment of potential for delayed neurotoxicity by repeated dosing in adult hens with monitoring of Che toxic esterase, and plasma butyrylcholinesterase activities. Fundam Appl Toxicol 1993;21:89-96.

37 Richardson RJ. Assessment of the neurotoxic potential of chlorpyrifos relative to other organophosphorus compounds: a critical review of the literature. $\mathcal{F}$ Toxicol Environ Health 1995;44:135-65.

38 Lotti M, Johnson MK. Repeated small doses of a neurotoxic organophosphate. Monitoring of neurotoxic esterase in brain and spinal cord. Arch Toxicol 1980;45:263-71.

39 Drevenkar V, Vasilic Z, Stengl B, et al. Chlorpyrifos metabolites in serum and urine of poisoned persons. Chem Biol Interact 1993;87:315-22.

\section{Fournal of Neurology Neurosurgery and Psychiatry - http://www.jnnp.com}

Visitors to the world wide web can now access the fournal of Neurology Neurosurgery and Psychiatry either through the BMJ Publishing Group's home page (http://www.bmjpg.com) or directly by using its individual URL (http://www.jnnp.com). There they will find the following:

- Current contents list for the journal

- Contents lists of previous issues

- Members of the editorial board

- Subscribers' information

- Instructions for authors

- Details of reprint services.

A hotlink gives access to:

- BMJ Publishing Group home page

- British Medical Association web site

- Online books catalogue

- BMJ Publishing Group books.

The web site is at a preliminary stage and there are plans to develop it into a more sophisticated site. Suggestions from visitors about features they would like to see are welcomed. They can be left via the opening page of the BMJ Publishing Group site or, alternatively, via the journal page, through "about this site". 